\title{
A Smart Phone based Application for Early Detection of Pregnancy Complications in Kenya
}

\author{
John Mbithi \\ Strathmore University \\ P.O Box 481-00521 \\ Nairobi, Kenya
}

\author{
Joseph Onderi Orero, PhD \\ Dean, Faculty of Information Technology \\ Strathmore University \\ P.O Box 59857-00200 \\ Nairobi, Kenya
}

\begin{abstract}
Lack of adequate information and timely response to pregnancy complications during prenatal care is a major cause of maternal mortality in Kenya. More women are dying from pregnancy and childbirth related causes such as preeclampsia, obstructed labor, infections, hemorrhage and high blood pressure.

The purpose of this study was to develop an expert system incorporated on a mobile phone to detect pregnancy complications before birth. The system used rule based system to determine whether a mother has maternal risks and recommends prenatal care advice based on the condition of the expectant mother.
\end{abstract}

\section{Keywords}

GSM- Global Systems for Mobile Communications (GSMA, 2013)

Mobile Application or Mobile App or App - This is an application developed for small hand held devices that come either pre-installed on phones during manufacture or downloaded by customers from various mobile software distribution platforms. (Viswanathan, 2013)

Expert System- A computer program that attempts to act like a human expert on a particular subject area (Zwass, 1985)

e IMCI -electronic Integrated Management of Childhood Illness

ES - Expert System

HIV/AIDS-Human Immunodeficiency

Virus

Infection/Acquired Immunodeficiency Syndrome

\section{INTRODUCTION}

Complications related to pregnancy and childbirth are among the leading causes of morbidity and mortality among Kenyan women. According to previous estimates, Kenya's maternal mortality rate remains at disconcertingly high levels: 488 deaths per 100,000 live births (KDHS, 2008).

According to Volunteer Services Organization Jitolee (2012), the lifetime risk of maternal death in 2009 was 1 in 39 women, making it among the worlds' highest. Hospitals studies suggest that the majority of these deaths are due to obstetric complications, including hemorrhage, sepsis, eclampsia, obstructed labor and the low proportion of deliveries conducted by skilled birth attendants as well as poor staffing among other causes. This causes are however preventable with access to information and early diagnosis and treatment.

The discipline of $\mathrm{m}$-health has been gaining ground as mobile device penetration rates grow rapidly, increasingly prompted by plunging hardware and usage costs, as developing world consumers adopt this accessible communication technology (Iluyemi, 2007). Mobile penetration in Africa is expected to increase to $82 \%$, in 2014. Additionally, the increase in penetration of smartphones as well as the $3 \mathrm{G}$ and $4 \mathrm{G}$ networks will provide a significant boost to the use of the mobile platform for providing healthcare services. Thus, the feasibility of mobile devices supporting healthcare is greater than ever before. Mobile health - the use of mobile communication and devices for providing healthcare services or achieving health outcomes - stands at a significant inflection point (Siddharth, 2012).

This study seek to research and develop an expert based system on a mobile phone which could assist mothers in detecting complications at birth and seek the attention of a doctor. An expert system is defined as an automated reasoning system that attempts to mimic the performance of a human expert (Rosenman, 1985). This would assist in reducing the delays in decision making, or assumptions and ensure that the mother is safe.

\section{M- HEALTH IN CONTEXT}

M-Health is a component of e-Health. M-Health or mobile health is termed as a medical and public health practice supported by mobile devices, mobile phones, patient monitoring devices, personal digital assistants (PDA's) and other wireless devices (WHO,2011).

Figure 1: Relationship between Health, E-health and Mhealth (Odongo, 2010)

According to Istepanian et al., (2009), the advances in the mobile technologies will soon prove to have a powerful impact on the way different health care delivery organizations will reshape the future of these services globally by utilizing such emerging technologies for the enhancement of future healthcare services. This is already true as m-Health is already redefining the original concept of telemedicine as "medicine practiced at a distance" to include the new mobility and "invisible communication technologies" to reshape the future structure of global healthcare systems.

Mobile technology, like basic cell phones can be used to save the lives of mothers in child birth and improve the care of newborns and children reaching underserved populations in remote areas (WHO, 2010).

The discipline of $\mathrm{m}$-Health in Kenya has been gaining ground as mobile device penetration rates grow rapidly, increasingly prompted by plunging hardware and usage costs, as developing world consumers adopt this accessible communication technology (Donner, 2004; Iluyemi, 2007). Case studies have been recorded in the instances of using Short Message Service (SMS) for HIV/AIDS prevention and 
control, and for treatment of tuberculosis in South Africa (Atun, 2005).

Mobile technologies have a number of key features that give them an advantage over other information and communication technologies in particular activities within health care and public health. Firstly, majority of the mobile devices have wireless cellular communication capability, providing the potential for continuous, interactive communication from any location such as telephone calls, text and multimedia messaging and also internet access via Wireless Application Protocol (WAP) or mobile broadband internet. Secondly, the devices are portable because of their small size, low weight and rechargeable, long-life battery power. Finally, many mobile devices have sufficient computing power to support multimedia software applications. The combination of these features varies between specific devices and their relative importance will change with the health activity in which they are used. However, with advances in technology development, single devices increasingly possess many or all of these functions.

Limited access to health services is linked to low antenatal care and maternal and perinatal mortality. Mhealth could be a very useful strategy for low and medium income countries to improve antenatal care. This could be attributed due to the fact that the general population nowadays is becoming more health conscious and with the proliferation of mobile phones with internet capability, there is need for an expert system that will not replace a doctor assist a doctor to offer medical care (Nguyen, 1996).

\subsection{Expert Systems in Health Care}

An expert system is computer software that employs knowledge captured in a computer program to solve difficult problems that usually require human expertise. Well-designed expert systems (ES) imitate the reasoning process experts use to solve specific problems and can be used by no experts to improve their problem-solving capabilities and by experts as knowledgeable assistants. Figure 2-8 shows how the structure of expert systems

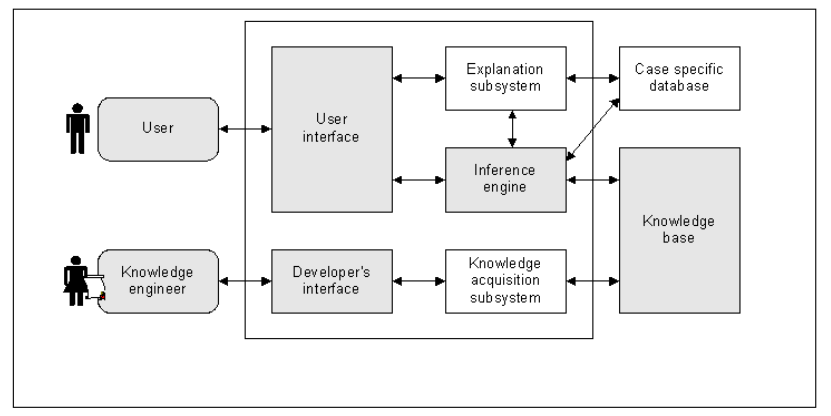

Figure 2: Typical Structure of an Expert System (Engelmore et al, 1993)

An expert system's knowledge is obtained from expert sources and coded in a form suitable for the system to use it in its inference or reasoning processes. The expert knowledge must be obtained from specialists or other sources of expertise, such as texts, journal articles and data bases. This type of knowledge usually requires much training and experience in some specialized field such as medicine, geology, system configuration, or engineering design. Once a sufficient body of expert knowledge has been acquired, it must be encoded in some form, loaded into a knowledge base, then tested, and refined continually throughout the life of the system.
These programs use a collection of facts, rules of thumb, and other knowledge about limited field to help make inferences in the field. This differ substantially from conventional computer programs in their goals may have no algorithm solution, and they must make inferences based on incomplete or uncertain information.

Many professions including medicine have standard operating procedures for the performance of their tasks. In the construction of Expert Systems, knowledge engineers have exploited this fact in devising heuristic rules that mimic the standard practice among such personnel (i.e., experts). Much medical knowledge is heuristic in nature; for example, an experienced doctor might use a rule in diagnosis such as: «If symptoms $\mathrm{A}$ and $\mathrm{B}$ are observed then $\mathrm{C}$ is plausible but certainly not D»

According to (Echeverria, 1999), Expert Systems in medicine are knowledge data bases founded on patient data, literature searches and opinions of experts. With these systems it is for instance possible to test or to take clinical decisions. These systems are, among other uses, employed for quality assurance and documentation, as a teaching instrument as well as a knowledge base. The possibility of their use in the application of diagnostic and staging protocols is particularly interesting. Expert Systems will enable specialist expertise (a rare commodity) to be available to non-specialists such as general practitioners. The development and commercial availability of Expert Systems programming tools called shells make it certainly easier to develop consultations systems, even to non-experienced users. In this study we explored expert systems in detection of risks in expectant mothers.

\section{SYSTEM DESIGN AND IMPLEMENTATION}

System architecture refers to the conceptual model that defines the structure, the behavior and views of a system. It enables the developer establish the basic structure of the proposed mobile application and what the systems needs to be and to do. The m-health application for early detection of risks during pregnancy was developed based on the architecture shown on Figure 3-1.

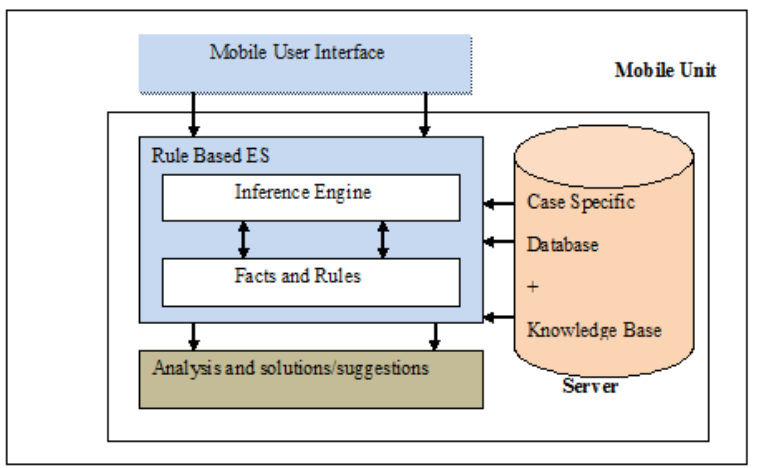

Figure 3: Structure of Rule based Expert System

\subsection{Mobile User Interface}

The Mobile User Interface is the graphic and touch -sensitive display on a mobile device. In our case the expectant mother interacted with the system through a user interface, It may use menus, natural language or any other form of computer interaction. The User Interface focuses on human concerns such as ease of use, reliability and reduction of fatigue. 


\subsection{The Knowledge Base}

The knowledge base contains domain specific knowledge acquired from the domain expert. Can consist of object descriptions, problem solving behavior, constrains heuristics and uncertainties.

In our research the knowledge base contained domain specific knowledge acquired from doctors and information online. The information consisted of common problems that would face an expectant mother at different stages of birth.

\subsection{Inference Engine}

The inference engine is the logic that contains the rules of inference and related factual information, about a particular domain. Upon receiving the symptoms from the expectant mother the inference engine infers with high accuracy the type of illness and suggests the best inference.

In our research the Interference Engine contained the logic using forward chaining. This involved assigning values to attributes, evaluating conditions and analyzing to see if all conditions are satisfied.

\subsection{Use Case Diagram}

The use cases are UML (Unified Modeling Language) diagrams used during the analysis phase of project to identify and partition the system, their main functionality is to separate the actors and the use cases. Actors represent roles that could be played by users of the system. These users could be humans other computers, pieces of hardware, or even other software systems. The only criterion is that they must be external to the part of the system being partitioned into use cases. They must supply stimuli to the part of the system and receive outputs from it.

\section{a. Description- Select Symptoms}

Actors- Registered User

Pre-condition- User is logged in

Main Success Scenarios

1. The user has provided personal information such as weight, age and blood pressure.

2. Description- View Prenatal Risks

Actors- Registered User

Pre-condition- User is logged in

Main Success Scenario

1. The user has logged in

\section{The user selects view prenatal risks}

b. Description - View Diagnosis Result

Actors- Registered User

Pre-condition- User is logged in and has provided personal information

Post condition- User has selected symptoms

Main Success Scenario

The user has provided bio information such as date of birth and how many weeks pregnant the she is.

The user selects the symptoms

The expert system checks the information against rules and determines diagnosis.

\section{Alternative Flows}

1a. The user does not provide all personal details and selects symptoms, the user is informed to complete filling personal information.

For Example:

IF: The user does not fill in bio information

THEN: prompt "Kindly fill in all Bio Information"

2a. The user does not select symptoms, the expert system will diagnose considering no selected symptoms present.

IF: The patient has no symptoms selected

AND: Blood Pressure is okay

THEN: Conclude that patient is okay

\subsection{Sequence Diagram}

The sequence diagram is a diagram that graphically depicts how objects interact with each other via sending and reception of messages in the execution of a use case or operation. In the mobile application for detection of risks during pregnancy once the login message is sent the application validates the user credentials and either accepts or rejects the login.

The user then enters her bio information, this includes her age, number of weeks pregnant, blood pressure and weight, the application will then ask her whether she is experiencing a chain of symptoms in order to deduce a conclusion. Once the deduction is reached the user is informed and if she needs to perform the check again she does it. 


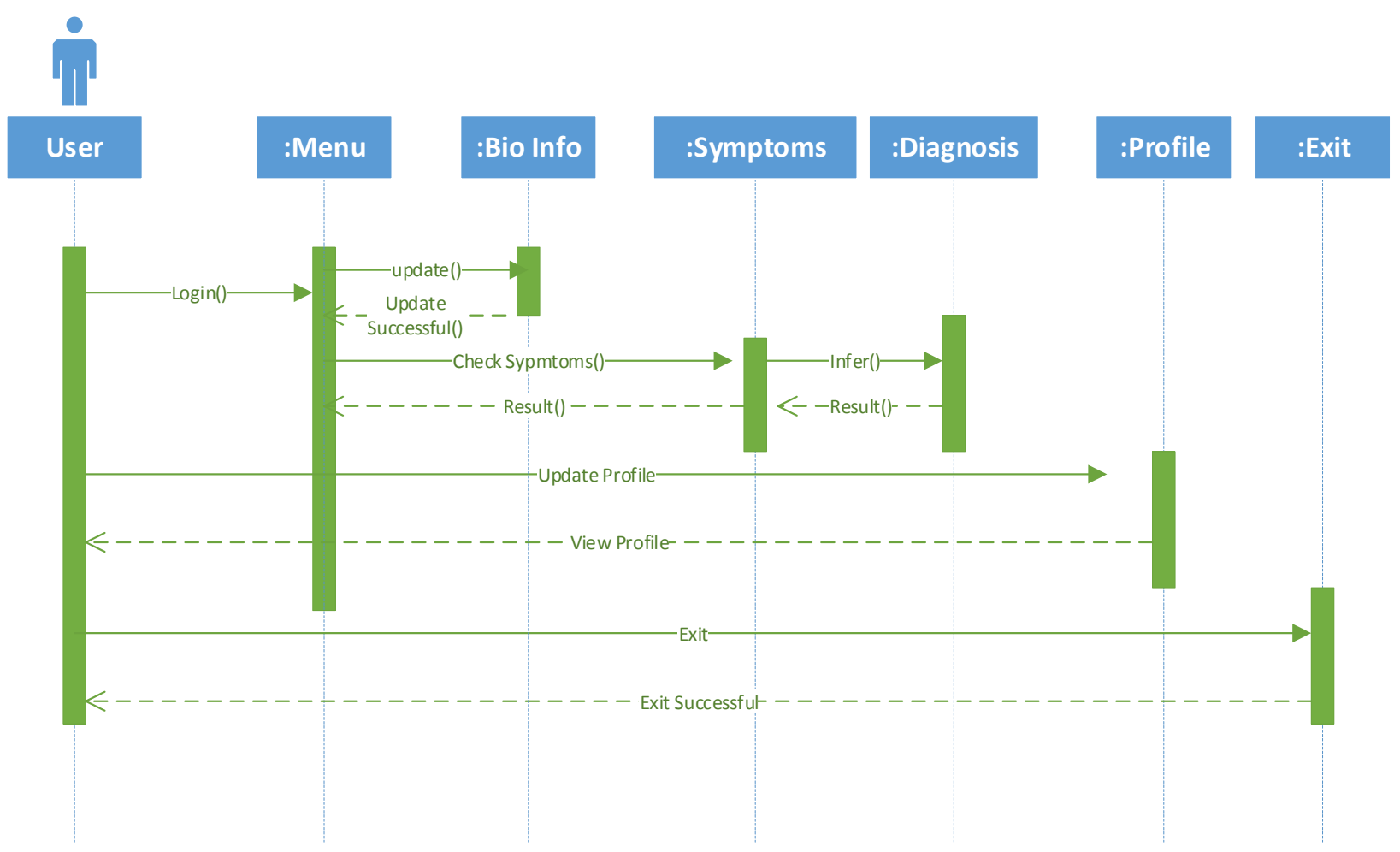

Fig 4: Early Detection of Risks Sequence Diagram

\section{RESEARCH METHODOLOGY AND DESIGN}

This research adopted a quantitative research design. The questionnaires were used to access qualitative data by collecting user requirements from clinicians which would be used to develop the mobile application. In this way, verification deeper explanation and appropriation of findings of the survey was sought for the sake of accuracy in interpretation of data. Quantitative data collection methods were used as they are centered on the quantification of relationships between variables. These quantitative datagathering instruments established relationship between measured variables in the demographic, mobile device specifications and survey proper sections of the questionnaire used. Through the use of these methods, the researcher was detached from the study and the final output was context free.

\subsection{Research Participants}

To determine how expectant women detect risks during the pregnancy period, a total of 15 respondents were asked to participate. The participants who qualified for the sample selection were expectant women or had already given birth and owned an android smartphone. These criteria ensured that the participants understood the nature of the questionnaire and its use for detection of risks during pregnancy.

Table 1. Questionnaire for Profile

\begin{tabular}{|l|l|l|l|}
\hline Question & & & \\
\hline $\begin{array}{l}\text { Select your age } \\
\text { bracket }\end{array}$ & $\mathbf{1 8 - 2 4}$ & $\mathbf{2 5}-\mathbf{3 5}$ & $\mathbf{3 6}-\mathbf{4 5}$ \\
\hline $\begin{array}{l}\text { Indicate your area } \\
\text { of residence }\end{array}$ & & \\
\hline
\end{tabular}

\begin{tabular}{|l|l|l|l|}
\hline Question & & & \\
\hline $\begin{array}{l}\text { Select your level } \\
\text { of education }\end{array}$ & $\begin{array}{l}\text { Secondary } \\
\text { School Level }\end{array}$ & $\begin{array}{l}\text { Graduate } \\
\text { School } \\
\text { Level }\end{array}$ & $\begin{array}{l}\text { Post } \\
\text { Graduate } \\
\text { Level }\end{array}$ \\
\hline
\end{tabular}

\subsection{Research Instruments}

Survey questionnaires were used as the main instrument for research. The questionnaires were designed as both simple closed and open ended questions.

The questions were structured using the Likert format. In the Likert survey type, five choices were provided for every question or statement. The choice represents the degree of agreement each respondent has on the given question. The scale below was used to interpret the total responses of all the respondents for every survey question by computing the weighted mean:

Table 2. Questionnaire Structure

\begin{tabular}{|c|c|}
\hline Range & Interpretation \\
\hline 5 & Strongly Agree \\
\hline 4 & Agree \\
\hline 3 & Neutral \\
\hline 2 & Disagree \\
\hline 1 & Strongly Disagree \\
\hline
\end{tabular}

\subsection{Reliability of Instruments}

An instrument is considered if the same result is obtained from the method on repeated occasions. It can depend on various factors (the observers, the tools, the methods, the context, the sample). In this research a questionnaire was used 
to gather the requirements and the mobile application was developed based on these requirements and then another questionnaire was used to asses on the usability of the mobile application to the users.

\subsection{Piloting}

Based on the requirements that were elicited from the requirements analysis, a pilot was conducted to enrolled expectant mothers in Nairobi County through random sampling and using blogs and social media such as facebook and twitter. The mothers were asked to download the application from a link provided to them and instructions on how to use it were mailed to the selected respondents.

A usability questionnaire based on likert scale was then be sent to the mothers who later on provided feedback.

\subsection{Ethical Considerations}

During the study I seek formal consent from each respondent and their rights were affirmed to them prior the interview. Besides, the convenience, confidentiality, privacy and comfort of the participants were of consideration. Confidentiality was for example guaranteed by giving each respondent a code which is maintained throughout the study.

\subsection{System Specification}

The application is downloaded and installed on the user's phone. It relies on the phone memory however it does not take up a lot of internal memory space. It's is compatible to all phones that run on android.

The software tools used for developing the mobile application were Eclipse Indigo which was the Integrated Development Environment, and the language used was Java and the database of preference was SQLite.

\subsection{Experimental Tests and Results}

Of the 15 respondents interviewed the study found that 9 agreed the application was able to assist in detecting risks at birth.

From the results of the research it was evident that most expectant mothers are open to mobile applications that can assist them to easily detect risks at birth. This was attributed to the need of the mothers to ensure that their unborn children were at good state of health.

Expectant mothers agreed that it is important to keep a mother informed of risks that could be present at before birth, because many cases are identified in later stages of pregnancy or during prenatal visits.

\section{Requirements Analysis}

Requirements Analysis is the first process in the software development process. It assists the developer determine how to refine existing requirements to develop the software. In this research a pre-test was conducted; and data was gathered from a sample group of 15 respondents. Before conducting the pretest research questionnaire, the significance, rationale and purpose of the study was provided to the respondents. The objective of the pre-test was to establish what expectant mothers would expect from a mobile application for the detection of risks during pregnancy; this was then analyzed and interpreted and the application developed. The chapter discusses the result of the pre-test questionnaire from the selected participants. Specific questions adapted for expectant women in urban areas indicating important determinants regarding detection of risks at birth.
Table 3: General Mobile Phone Service and Device Information

1. Do you own a smart phone? Yes ( ) No ( )

\begin{tabular}{|l|l|l|l|l|l|}
\hline $\begin{array}{l}\text { Manufac } \\
\text { turer }\end{array}$ & $\begin{array}{l}\text { Samsun } \\
\text { g }\end{array}$ & Nokia & Ideos & $\begin{array}{l}\text { Ericss } \\
\text { on }\end{array}$ & $\begin{array}{l}\text { Others } \\
\text { (specify } \\
\text { below) }\end{array}$ \\
\hline $\begin{array}{l}\text { Phone } \\
\text { Model }\end{array}$ & & & & & \\
\hline
\end{tabular}

2. Do you use your phone to download applications on pregnancy information? Yes () No ()

\subsection{Experimental Tests and Results \\ 4.8.1 Acceptability, Operability and \\ Effectiveness}

Out of the 15 respondents interviewed the study found that 9 agreed the application was able to assist in detecting risks at birth.

From the results of the research it was evident that most expectant mothers are open to mobile applications that can assist them to easily detect risks at birth. This was attributed to the need of the mothers to ensure that their unborn children were at good state of health.

Expectant mothers agreed that it is important to keep a mother informed of risks that could be present at before birth, because many cases are identified in later stages of pregnancy or during prenatal visits.

Additionally majority of the expectant mothers asked if they could have tips on detecting search risks so as to be kept informed.

The study also found that, the expectant mothers preferred a mobile application that is resident on the phone as opposed to one that makes connection to the internet.

\subsection{Usability Test Analysis}

\subsubsection{Confidence in using the mobile application to detect risk during pregnancy}

9 of the respondents were confident in using the application to detect risks in pregnancy. This was due to the fact that majority of the mobile applications were information based and not expert systems.6 of the respondents were not confident in using a mobile phone to detect risks at birth, this is because they were not so comfortable with the idea of an application being able to detect a pregnancy complication.

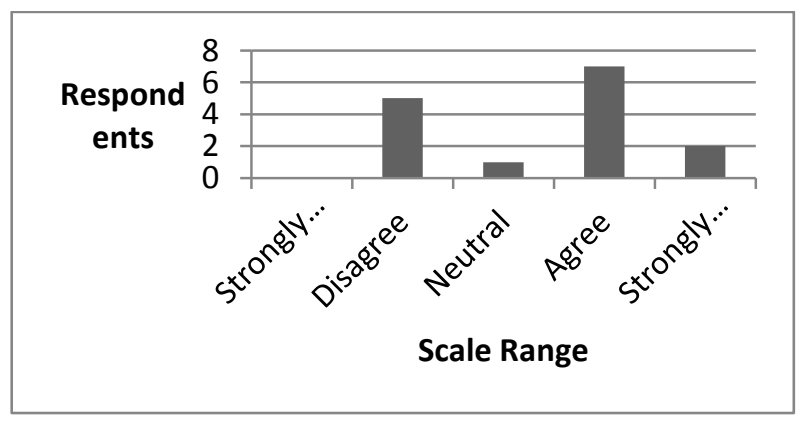

Figure 5: Confidence in using the application 


\subsubsection{Importance on information on maternal risks during pregnancy using a mobile application}

All the respondents agreed that it was vital to keep a mother informed on any risks that could affect her pregnancy. 9 strongly agreed whereas 6 agreed. This is because they saw the importance of having a risk free birth. The question was set to find out whether the expectant mothers seek other sources of information. From the findings $67 \%$ of the respondents would prefer being informed on maternal risks during pregnancy.

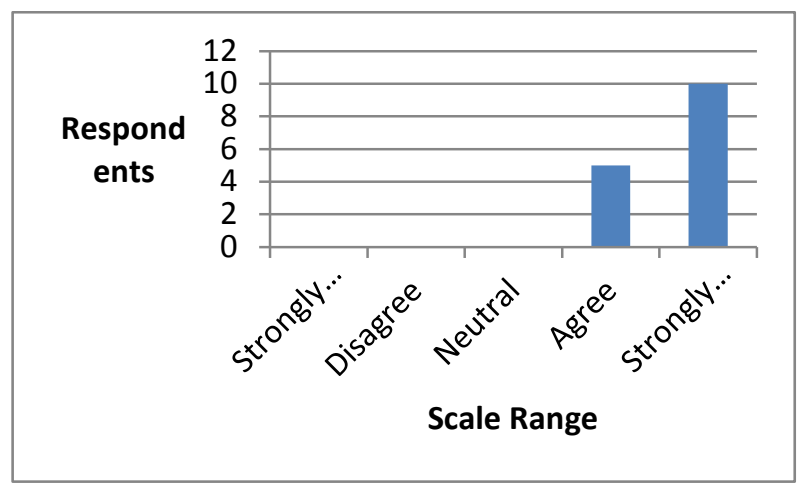

Figure 7: Importance of being informed of maternal risks during pregnancy

\subsubsection{Ease of download and access of the mobile application on the mobile phone}

This question elicited interesting responses as 10 strongly agreeing and conversely 5 strongly disagreeing. The respondents who agreed used their phones to download other applications apart from pregnancy related applications and as such they found it an easy means to download and access information. However the remaining six experienced problems with downloading since it was their first time and others because a user guide was not available.

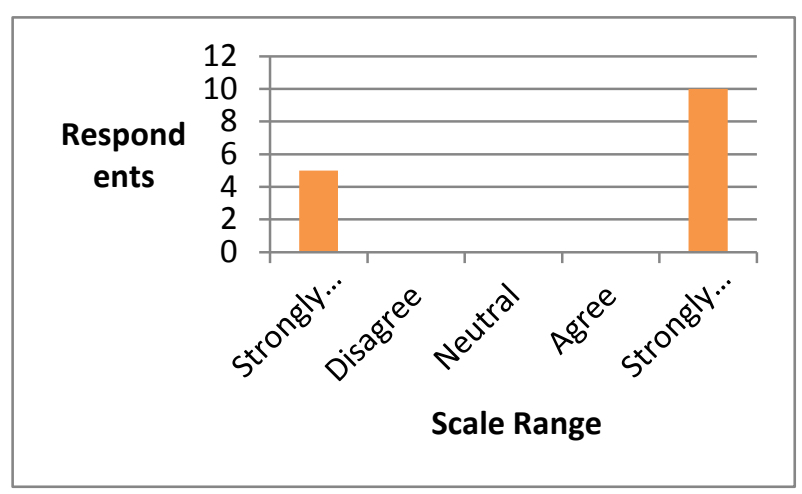

Figure 6: Ease of downloading and accessing information

\section{ACKNOWLEDGMENTS}

My sincere and deepest gratitude goes to God for His favor and guidance throughout this entire program and dissertation.

I am indebted to my supervisor Dr. Joseph Onderi Orero for his invaluable guidance and keen supervision that led to the successful completion of this dissertation. I also appreciate the advice and guidance of all other lecturers from Strathmore University -Faculty of Information Technology and iLab Africa. Finally, I would like to thank my parents and siblings for their support encouragement throughout this Master's program and the whole Safaricom Academy fraternity.

\section{REFERENCES}

[1] Ambert, A. M. Adler, A.P., Adler, P. \& Detzner, D.F. (1995). Understanding and evaluating qualitative research Journal of marriage and the family, Vol. 57, 879-893.

[2] Angelidis, P. (2008). Mobile Telemonitoring Insights. Medical informatics: Concepts, methodologies, tools, and applications, 1, 107-112.

[3] Atun, R. A., \& Sittampalam, S. R. (2005). Uses and benefits of SMS in healthcare delivery.RetrievedOctober22,2008, from http://www3.imperial.ac.uk/portal/pls/portallive/docs/1/5 375912.PDF

[4] Baby Center. (2013). My Pregnancy Today. Retrieved from Baby Center. Retrieved May 19 2013,from http://www.babycenter.com/my-pregnancy-today-app.

[5] Baker, B. (2006). Mobile phone text message based consultation: An investigation of current practice and associated best practice recommendations. Retrieved November 22, 2008, from http://www.ehealthnurses.org.uk/pdf/mobreport.pdf

[6] Bali, S., \& Singh, A. J. (2007). Mobile phone consultation for community health care in rural north India. Journal of Telemedicine and Telecare 2007, 13(8), 421-424. Retrieved November 15, 2008, from http://jtt.rsmjournals.com/cgi/reprint/13/8/421

[7] Burns N \& Grove SK (1997). The practice of Nursing Research Conduct, Critique, \& Utilization. W.B Saunders and Co., Philadelphia.

[8] Charmaz, K. (2000). Grounded theory: Objectivist \& constructivist methods. Handbook of Qualitative Research, 2nd edition

[9] Chetley, A. (2006). Improving health, connecting people: The role of ICTs in the health sector of developing countries. Retrieved October 30, 2008, from http://www.asksource.info/pdf/framework2.pdf

[10] Cohen, P (1989). The handbook of Artificial Intelligence, Volume IV. Reading, Mass: Addison Wesley.

[11] Blascheke, S and Bokenkamp, K(2009). Using Mobile Phones to Improve Child Nutrition Surveillance. UNICEF. Retrieved from: http://mobileactive.org/research/using-mobile-phonesimprove-child-nutrition-surveillance-malawi

[12] Buys, Piet, Susmita Dasgupta, Timothy S. Thomas and David Wheeler. (2009). "Determinants of a Digital Divide in Sub-Saharan Africa: A Spatial Econometric Analysis of Cell Phone Coverage." World Development. 37(9).

[13] Center for Disease Control and Prevention. (2013, March 6). Women's Health.Retrieved February 27, 2012, from Become a Text4baby Partner: http://www.cdc.gov/women/text4baby/

[14] Chib, A. (2010). The Aceh Besar midwives with mobile phones project: Design and Evaluation perspectives using the information and communication technologies 
for health care development model. Journal of Computer-Mediated Communication, 500-501.

[15] Donner, J. (2004). Innovations in mobile-based public health information systems in the developing world: An example from Rwanda. Retrieved November 18, 2008, from http://jonathandonner.com/donner-mobhealth.pdf

[16] Engelmore, R. S. \& Feigenbaum, E.(1993) Expert Systems and Artificial Intelligence. Knowledge-based systems in Japan. Japanese Technology Evaluation Centre.

[17] Ghebrehiwet, M. and Morrow, R.H. (2002). Delay in seeking and receiving emergency obstetric care in Eritrea.

[18] GSMA. (2013). Mobile Technology. Retrieved June 6th, 2013, from GSMA: http://www.gsma.com/aboutus/gsmtechnology/gsm

[19] Guidotti R and Jobson D,. (2005). Safe Motherhood. Detecting pre-eclampsia : A practical guide.

[20] Iluyemi, A. (2007). Mobile e-Learning for community based health workers in developing countries: A proposed model. Paper presented at The First International m-libraries Conference, Milton Keynes, United Kingdom

[21] International Telecommunications Union (2011), Mobile Cellular Subscriptions. Reviewed December 2011
[22] IRIN (2009). Ghana: Cell phones cut maternal deaths. Last accessed on 09/02/2012: http://www.irinnews.org/report.aspx?ReportId=87261

[23] Kinkade S., \& Verclas, K. (2008). Wireless technology for social change: Trends in mobile use by NGOs. United Kingdom: UN Foundation-Vodafone Group Foundation Partnership.Retrieved November 15, 2008, from http://mobileactive.org/files/MobilizingSocialChange_ful 1.pdf

[24] Kothari C. R (2004). Research Methodology: Methods and Techniques

[25] Lagsten, J. (2011). Evaluating Information Systems according to Stakeholders: A Pragmatic Perspective and Method. The Electronic Journal Information Systems Evaluation Volume 14 Issue 1, (pp73-88)

[26] McConnell, H., Chathoth, P., Pardy, A., Boostrom, C., Boostrom, E., \& Louw, K. (2008). Leapfrog technologies for health and development. Global Forum Update on Research for Health, 5, 130-135.

[27] Mechael, P.N (2009). "Mobile Phones for Mother and Child Care: Case Study for Egypt".

[28] Ministry of Health (MOH)(1996). National Reproductive Health Strategy, 1997-2010. Nairobi:MOH.

[29] Mishra, S., \& Singh, I. P. (2008, July 13). mHealth: A developing country perspective. Paper presented at the Making the eHealth Connection: Global Partnerships, Local Solutions Conference 2008, Bellagio, Italy. 